\title{
Synthesis and Textural Properties of Unsupported and Supported Rutile $\left(\mathrm{TiO}_{2}\right)$ Membranes
}

\author{
Krishnankutty-Nair P. Kumar, ${ }^{a}$ Klaas Keizer, ${ }^{a}$ Anthonie J. Burggraaf, ${ }^{a}$ Tatsuya Okubo ${ }^{b}$ and Hidetoshi \\ Nagamoto ${ }^{b}$ \\ ${ }^{a}$ Laboratory for Inorganic Chemistry, Materials Science and Catalysis, Faculty of Chemical \\ Technology, University of Twente, 7500 AE Enschede, The Netherlands \\ ${ }^{b}$ Engineering Research Institute, Faculty of Engineering, The University of Tokyo, 2-11-16 Yayoi, \\ Bunkyo-ku, Tokyo 113, Japan
}

\begin{abstract}
Two approaches were postulated for improving the stability of porous texture of titania membranes: (1) retarding the phase transformation and grain growth; (2) avoiding the phase transformation. Based on the second approach, rutile membranes were made directly from a rutile sol, prepared by the precipitation of titania on $\mathrm{SnO}_{2}$ nuclei. The rutile membranes were stable up to $800{ }^{\circ} \mathrm{C}$, with a porosity of ca. $40 \%$, whereas normal titania membranes (starting with anatase) show very little porosity above $600^{\circ} \mathrm{C}$. Alumina substitution retards grain growth and pore growth at $850{ }^{\circ} \mathrm{C}$ for unsupported as well as supported membranes.
\end{abstract}

Keywords: Ceramic; Membrane; Rutile; Titania; Tin oxide

There is increasing interest in the design and development of chemically stable materials with stable porous texture for high-temperature separation and catalytic applications. Hightemperature-withstanding membrane modules can be employed directly in a chemical process line. This is economically advantageous because there is no cooling of the feed gas and no heating process after separation. Catalysts that can be used at relatively high temperatures are also gaining importance because it is economical to carry out many chemical reactions at elevated temperatures, for example the gas-phase partial oxidation of methane to synthesis gas. ${ }^{1,2}$

Titania membranes are projected as possible candidates for catalytic membrane applications. ${ }^{3-6}$ It has been shown that ${ }^{7}$ the unsupported titania membranes lose their porosity and surface area completely when calcined at $c a .500^{\circ} \mathrm{C}$ for $8 \mathrm{~h}$. Two major causes of reductions in surface area and porosity were identified: (1) the crystallite growth of the anatase phase before the phase transformation; (2) the enhanced sintering and grain growth of the rutile phase as a result of the phase transformation. ${ }^{7}$ Of these processes, that happening as a result of the phase transformation causes a drastic reduction in surface area and porosity compared with the other.

In general, there are two approaches to improving the thermal stability of a system when the processes responsible for the instability, are known. The first approach is to retard the processes that cause the instability. In the case of titania this can be realized by retarding the crystallite growth of the anatase phase (cause 1) and the phase transformation rate, which in turn retards the enhanced sintering (cause 2). It should be noted that the phase transformation by itself is not the cause of pore growth and porosity reduction, but the enhanced sintering as a result of the transformation process and the grain growth of the transformed rutile phase will contribute to the drastic reduction in porosity and in pore growth. Therefore it is thought that retardation of the phase transformation will improve the stability of the porous texture because of the consequent retardation of the sintering rate. Results on the improvement of thermal stability by retarding the crystallite growth and (shifting) the phase transformation are discussed elsewhere. ${ }^{8}$

The second approach is to avoid completely the processes causing instability. This approach is not suitable for cause 1 , because it is practically impossible to avoid the crystallite growth process during heat treatment. Also completely avoiding the anatase to rutile transformation is thermodynamically impossible. However, the phase transformation can be avoided by making the rutile sol directly. This paper describes the results of our research in making rutile sols by the precipitation and growth of rutile particles on rutile-forming nuclei formed in situ during the cohydrolysis of titanium isopropoxide and $\mathrm{SnCl}_{4}$. Rutile is a chemically stable material with potential for applications in the fields of membranes and catalysis. The morphological stability of such a system is further enhanced by doping with, for instance, alumina or lanthana.

\section{The Titania System}

Titania exists in two tetragonal crystallographic forms. A metastable form, anatase, and a stable form, rutile. The volume free energy of the rutile phase is always lower than that of anatase. Therefore, on heat treatment the anatase phase transforms to the stable rutile form. Since the transformation is a non-reversible metastable to stable type, the transformation temperatures reported in the literature range from 450 to $1200{ }^{\circ} \mathrm{C}^{7-23}$ The temperature of transformation depends very much on the nature and structure of the precursor and the preparation conditions. The majority of the chemical methods of preparation yield the metastable anatase phase, which on further heat treatment gives the rutile phase. No clear explanation has been given to account for the initial formation of the metastable anatase phase. A possible explanation is based on the size and the strain energy effect of the small anatase crystallites, being $c a .6 \mathrm{~nm}$ for alkoxide-derived anatase. The critical size of the rutile particles might be higher than the particle size of anatase $(\mathrm{ca} .6 \mathrm{~nm}){ }^{8}$

\section{Experimental}

\section{Preparation of the Precursor Sol}

In almost all cases the as-prepared titania will be either amorphous or poorly crystallized in the anatase form. Precipitation carried out in highly basic conditions may result in the rutile phase. ${ }^{24}$ However, to the best of the authors knowledge, nobody has attempted to make a rutile sol by the 
hydrolysis of titanium alkoxide followed by the direct synthesis of rutile membranes.

The strategy behind these experiments was to select an oxide (for nucleation purposes) which always crystallizes in the rutile structure. Then titanium isopropoxide is cohydrolysed with a highly reactive compound of the cation of the selected oxide. In this process it is expected that the rutile nuclei will hydrolyse first and act as nuclei for the growth of the rutile phase of titania. $\mathrm{SnO}_{2}$ was selected as a suitable rutile former. The $a$ and $c$ values of the unit-cell parameters are not too different for both the systems. For $\mathrm{SnO}_{2} a=$ 0.4737 and $c=0.3186 \mathrm{~nm}$ and $\mathrm{TiO}_{2}$ (rutile) $a=0.4593$ and $c=$ $0.2958 \mathrm{~nm}$. Another reason to select $\mathrm{SnCl}_{4}$ is its availability and high reactivity. The high reactivity is important because during the cohydrolysis of titanium isopropoxide and $\mathrm{SnCl}_{4}$, the latter should react with water before titanium alkoxide to provide the nucleus for titanium oxide growth. Fig. 1 gives the different steps involved in the preparation of rutile sol. A solution of titanium isopropoxide (Janssen Chemicals) and $\mathrm{SnCl}_{4}$ in isopropyl alcohol was obtained in a dropping funnel. For $1 \mathrm{~mol}$ of titanium isopropoxide, $2 \mathrm{dm}^{3}$ of isopropyl alcohol was used. The amount of $\mathrm{SnCl}_{4}$ in the solution was varied to investigate the effect on the rutile phase formation (for details see next section). The alkoxide solution was transferred dropwise into a beaker containing a mixture of water and alcohol ( $9 \mathrm{vol} \%$ water) under vigorous stirring. The water : alkoxide molar ratio was kept at 20 . The hydrolysis reaction, which was carried out at room temperature $\left(25^{\circ} \mathrm{C}\right)$, yields a white gelatinous precipitate. The precipitate was washed three times with $c a .5 \mathrm{dm}^{3}$ of water to remove the residual alcohol and subsequently redispersed in an aqueous solution of $\mathrm{HNO}_{3}$ resulting in $\mathrm{A} \mathrm{H}^{+} / \mathrm{Ti}^{4+}$ ratio of $c a$. 0.5 .

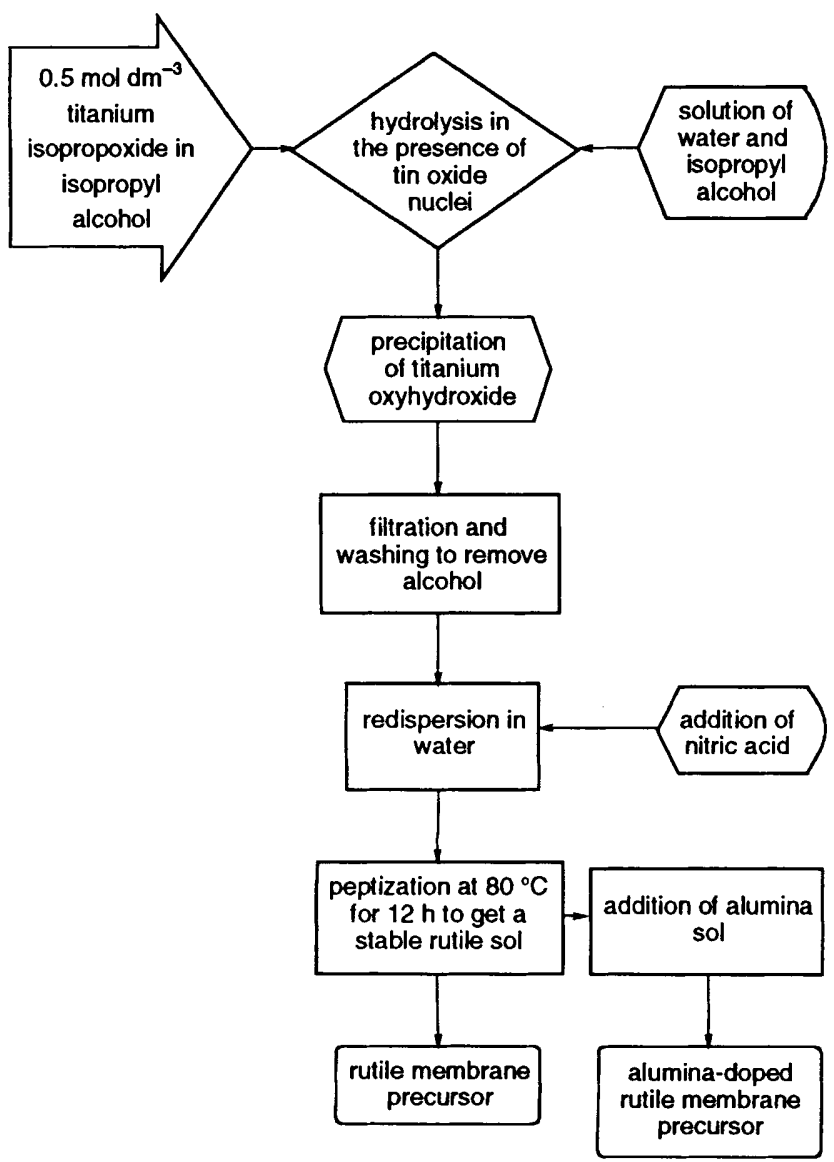

Fig. 1 Flow chart showing different steps involved in the synthesis of rutile membrane precursor sol
This dispersion was refluxed at $80^{\circ} \mathrm{C}$ for $c a .12-16 \mathrm{~h}$. The resulting sol has a pH of $c a .2$ and a concentration of $0.3 \mathrm{~mol}$ of $\mathrm{Ti}_{0.81} \mathrm{Sn}_{0.19} \mathrm{O}_{2}$. Anatase membrane precursor sol can be prepared in the same way but without the addition of $\mathrm{SnCl}_{4}$.

The alumina-doped rutile membranes were prepared by mixing the required amount of $1 \mathrm{~mol} \mathrm{dm}^{-3} \mathrm{AlOOH}$ (boehmite) ${ }^{8}$ sol with the rutile sol. The reasons for making aluminadoped rutile sol is explained later in the Discussion.

\section{Membrane Formation and Calcination Procedure}

Unsupported membranes were prepared by pouring the sol into a glass petri dish and dried at $40{ }^{\circ} \mathrm{C}$ and $60 \%$ relative humidity. The dried unsupported membranes had a thickness of $c a .12-15 \mu \mathrm{m}$ and were peeled off from the dish for further calcination. The dried membranes were heat treated at different temperatures ranging from 200 to $1000{ }^{\circ} \mathrm{C}$ with a heating rate of $100{ }^{\circ} \mathrm{C} \mathrm{h}^{-1}$ for $8 \mathrm{~h}$ in static air. After the soaking was finished the samples were furnace cooled to room temperature.

\section{Thermal Analysis and XRD}

The DTA/DSC and TG measurements were performed, using a Stanton Redcroft DSC and a Polymer Lab. Thermal Science system, with a heating rate of $10{ }^{\circ} \mathrm{C} \mathrm{min}-1$ in flowing air $\left(20 \mathrm{~cm}^{3} \mathrm{~min}^{-1}\right)$. DSC measurements for kinetic studies were performed at heating rates in the range $5-20{ }^{\circ} \mathrm{C} \mathrm{min}{ }^{-1}$. All the thermal analyses were carried out in air using alumina sample cups with $\alpha$-alumina as the reference material. The sample weight was kept at $40 \pm 2 \mathrm{mg}$.

Membranes calcined at several temperatures were subjected to X-ray diffraction measurements using a Philips PW 1710 diffractometer with $\mathrm{Cu}-\mathrm{K} \alpha$ radiation. In order to get very accurate data, only the step-scan technique was used. The step-scans were performed with a step size of $0.015^{\circ}(2 \theta)$, the time of counting at each step was $10 \mathrm{~s}$. The scanning range was $23-46^{\circ}(2 \theta)$. Crystallite sizes were calculated from the (110) reflection of rutile. To measure accurately the integrated intensity and the width at half maximum a pattern-fitting technique was applied. ${ }^{25}$ To carry out the fit Marquart nonlinear least-squares algorithm was used. ${ }^{26}$ The instrumental and wavelength-related broadenings were corrected by assuming a Cauchy relationship. ${ }^{27}$ Cauchy approximation accounts only for size broadening and the presence of strain is neglected. The crystallite size of anatase and rutile phases were calculated using the Scherrer relationship:

$$
D_{h k l}=K \lambda /\left(B_{h k l} \cos \theta\right)
$$

where $B_{h k l}$ is the width of the peak at half maximum. The value of $K$ varies from 0.9 to 1.4 depending on many factors including the shape of the primary crystallite. In this study a value of 1.38 is assumed for $K$. This $K$ value accounts for the deviation from pure Cauchy behaviour. The crystallite sizes calculated with this value are in good agreement with the sizes calculated from electron micrographs.

\section{Physical Adsorption Measurements}

$\mathrm{N}_{2}$ physisorption measurements of all the membranes were carried out at liquid-nitrogen temperature in a Micromeritics ASAP 2400 system. All the samples were degassed at $110^{\circ} \mathrm{C}$ prior to measurement.

\section{Results and Discussion}

\section{Synthesis of Rutile Membrane Precursor Sol}

Rutile membranes were prepared from the rutile precursor sol $\left(0.3 \mathrm{~mol} \mathrm{dm}^{3}\right)$ synthesized by the precipitation of titania 
with $\mathrm{SnO}_{2}$. The amount of $\mathrm{SnO}_{2}$ used for the synthesis was varied to get an idea about the minimum amount of $\mathrm{SnO}_{2}$ required to obtain $100 \%$ rutile phase in the as-precipitated stage. The sample shown in Fig. 2 gives the XRD pattern of titania membrane precursor gels, dried at $40{ }^{\circ} \mathrm{C}$ and $60 \%$ relative humidity ( $\mathrm{RH})$, containing different amounts of $\mathrm{SnO}_{2}$. The peaks marked $A$ and $R$ represent the anatase and the rutile phases. The sample corresponding to Fig. 2(a) contains only $5 \mathrm{~mol} \%$ of $\mathrm{SnO}_{2}$ and the spectrum is essentially that of anatase phase. The spectrum of the sample containing $c a$. $18 \mathrm{~mol}^{\%} \mathrm{SnO}_{2}$ shows that the material is a mixture of anatase and rutile [Fig. $2(b)$ ]. When more than $18 \%$ of $\mathrm{SnO}_{2}$ is present, the samples show essentially the rutile phase [Fig. $2(c),(d)]$. At ca. $40 \mathrm{~mol} \%$ of $\mathrm{SnO}_{2}$ the material becomes a solid solution of $\mathrm{TiO}_{2}$ and $\mathrm{SnO}_{2}$, as shown by the considerable peak shift with respect to the other rutile samples. The minimum amount of $\mathrm{SnO}_{2}$ required to get $100 \%$ rutile phase is found to be $c a .19 \mathrm{~mol} \%$ (Fig. 2). At this composition, there is ca. $21 \mathrm{vol} \%$ of $\mathrm{SnO}_{2}$ present (based on the densities of $\mathrm{SnO}_{2}$ and $\mathrm{TiO}_{2}$ which are 6.95 and $4.2 \mathrm{~g} \mathrm{~cm}^{-2}$, respectively). From X-ray line broadening and FE-SEM micrographs, the primary particle size of the precipitated rutile particles was found to be in the range $8-10 \mathrm{~nm}$. This implies that, for a composition containing $19 \mathrm{~mol} \% \mathrm{SnO}_{2}$, the size of the $\mathrm{SnO}_{2}$ nuclei formed during hydrolysis is in the range $4-6 \mathrm{~nm}$, assuming that the number of $\mathrm{SnO}_{2}-\mathrm{TiO}_{2}$ particles formed during hydrolysis is equal to the number of $\mathrm{SnO}_{2}$ nucleus. The following discussion is based on $100 \%$ rutile membranes containing $18.5 \mathrm{~mol} \%$ of $\mathrm{SnO}_{2}$ and on unsupported membranes unless otherwise mentioned.

\section{Thermal Analysis}

Fig. 3 gives the DTA and the TG results of the rutile membrane. In the TG trace there are two weight loss regions, the first, centred around $80^{\circ} \mathrm{C}$, represents the removal of physically adsorbed water. The second, at $c a .250{ }^{\circ} \mathrm{C}$, represents the dehydroxylation reaction and the decomposition of organics. In the DTA there are two dips in the low-temperature range corresponding to the two weight-loss regions of TG. There is a third peak at $c a .790^{\circ} \mathrm{C}$ and no weight loss can be seen in the TG trace. The origin of the peak is not clearly known, but it might be due to a recrystallization process followed by grain growth. Fig. 4 represents the crystallite sizes of the rutile membranes calcined at different temperatures for 5 min (heating and cooling rate is $100{ }^{\circ} \mathrm{C} \mathrm{h}^{-1}$ ). An increase in the crystallite size in the temperature range $700-800{ }^{\circ} \mathrm{C}$ is clearly observed. It should be noted that the presence of a

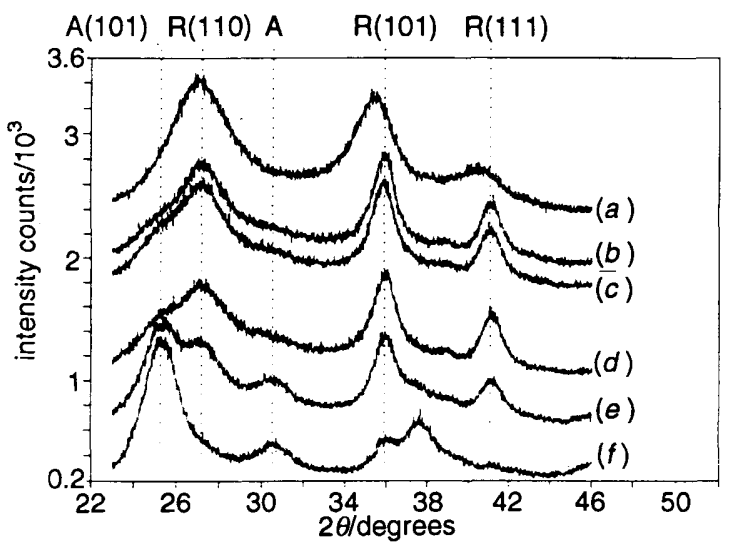

Fig. 2 XRD of the membrane precursor gels, dried at $40{ }^{\circ} \mathrm{C}$ and $60 \%$ $\mathrm{RH}$, containing different amounts of $\mathrm{SnO}_{2}:(a)$ 39, (b) 20, (c) 19, (d) $18.5,(e) 18$ and $(f) 5 \mathrm{~mol} \%$ of $\mathrm{SnO}_{2}$

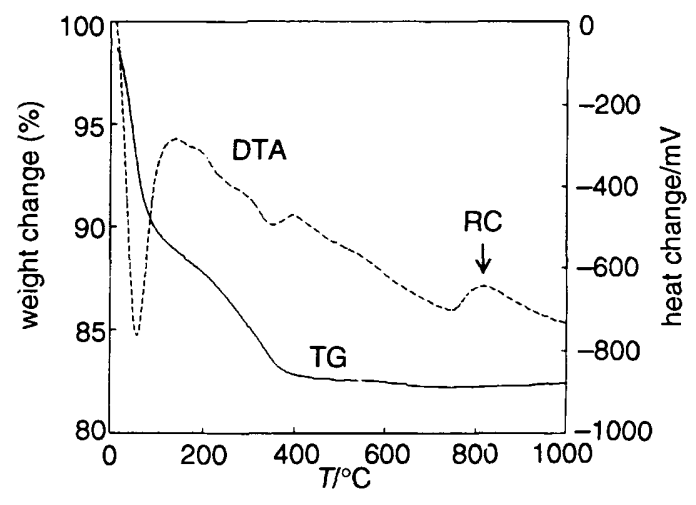

Fig. 3 DTA and TG patterns of the rutile membrane precursor gel containing $18.5 \mathrm{~mol} \% \mathrm{SnO}_{2}$

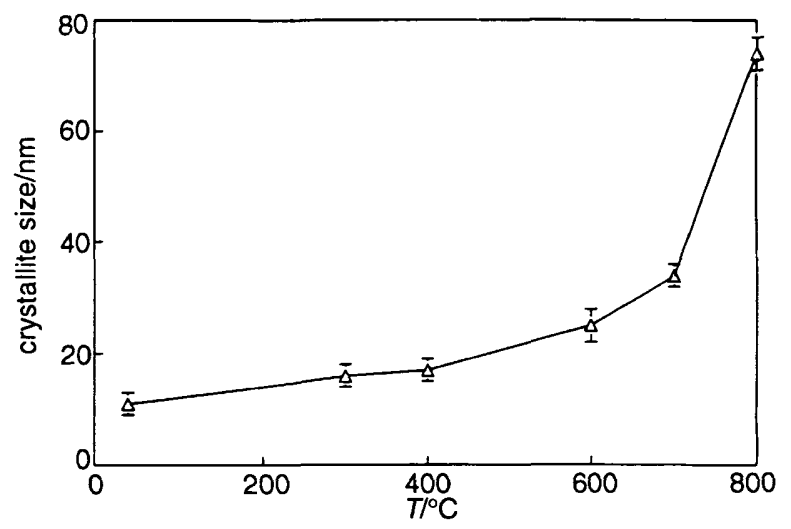

Fig. 4 Crystallite size of rutile membranes $\left(18.5 \mathrm{~mol}^{2} \mathrm{SnO}_{2}\right)$ subjected to heat treatments at different temperatures for $5 \mathrm{~min}$

DSC peak corresponding to crystallite growth does not indicate that there is no grain growth below that peak temperature. The peak represents the temperature at which the crystallite growth rate is the highest at the given heating rate. The XRD given in Fig. 5 clearly shows that there is no phase other than rutile present in the membranes from the gel state up to $800{ }^{\circ} \mathrm{C}$ (for Miller indices see Fig. 2). The peaks get narrower with increasing temperature and there is a sudden sharpening from 700 to $800^{\circ} \mathrm{C}$. This is in agreement with the DTA peak at $c a .790{ }^{\circ} \mathrm{C}$ corresponding to the grain growth.

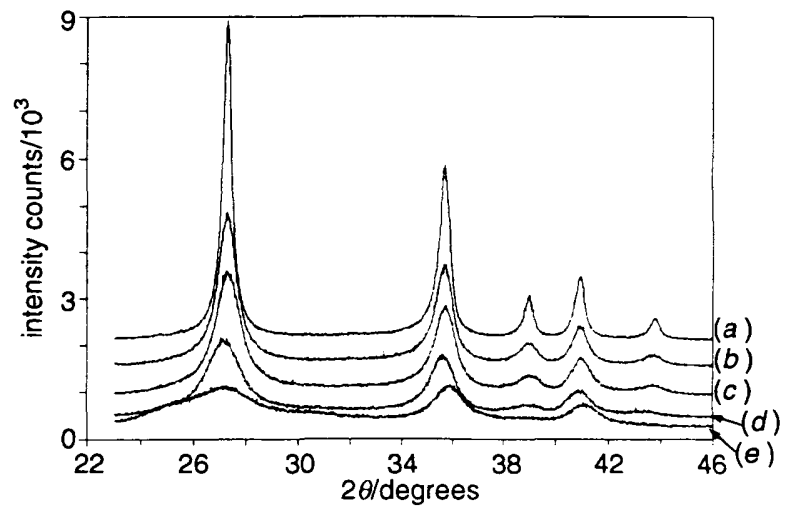

Fig. 5 XRD of the rutile membrane $\left(18.5 \mathrm{~mol}^{\circ} \mathrm{SnO}_{2}\right)$ calcined at different temperatures: (a) 800, (b) 700, (c) 600, (d) 400, and $(e) 40{ }^{\circ} \mathrm{C}$ (gel) 


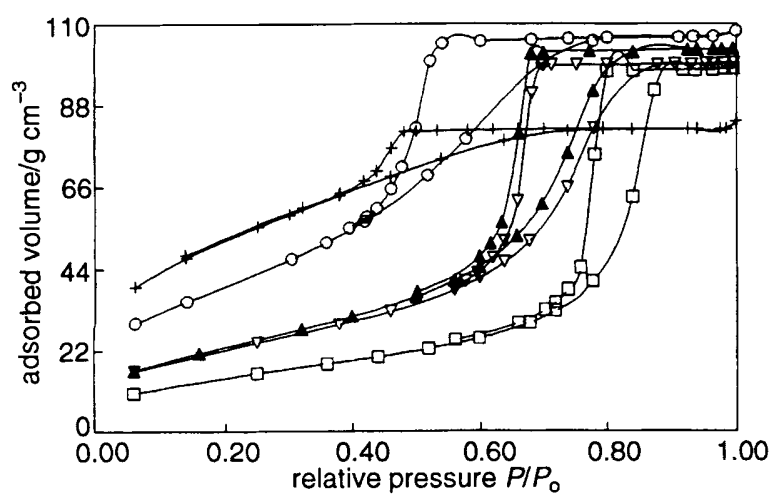

Fig. 6 Nitrogen physisorption isotherms of rutile membranes (18.5 mol\% $\mathrm{SnO}_{2}$ ) calcined at different temperatures ranging from 300 to $600{ }^{\circ} \mathrm{C}$ for $8 \mathrm{~h}:(+) 40,(\bigcirc) 300,(\Delta) 400,(\nabla) 500$ and $(\square) 600{ }^{\circ} \mathrm{C}$
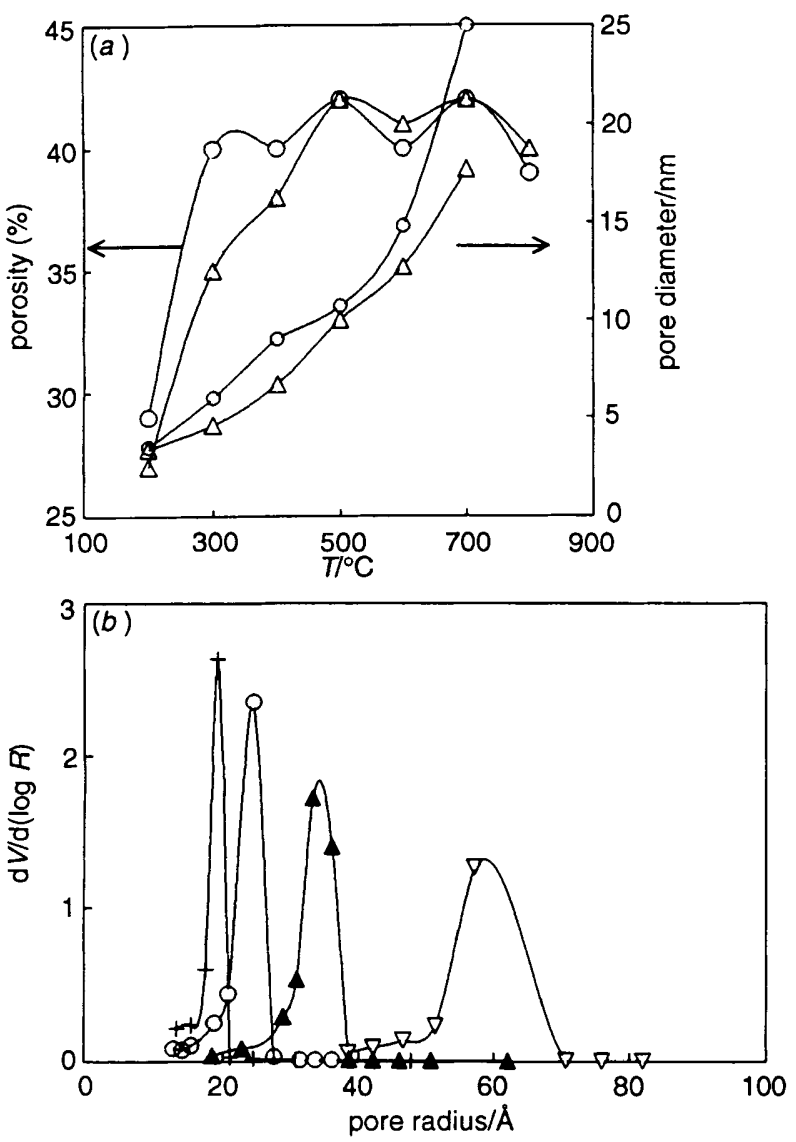

Fig. 7(a) Porosity and average pore diameter of unsupported rutile membranes $\left(18.5 \mathrm{~mol}_{0} \mathrm{SnO}_{2}\right)$ calcined at different temperatures for $5 \mathrm{~min}(\triangle)$ and $8 \mathrm{~h}(O) .(b)$ Pore size distribution of unsupported rutile membranes heated at $(+) 200,(\bigcirc) 300,(\Delta) 400$ and $(\nabla) 600^{\circ} \mathrm{C}$ for $8 \mathrm{~h}$

\section{Textural Evolution}

Fig. 6 represents the $\mathrm{N}_{2}$ physisorption data for the rutile membranes calcined at different temperatures. The shape of the isotherms correspond to the type IV classification with

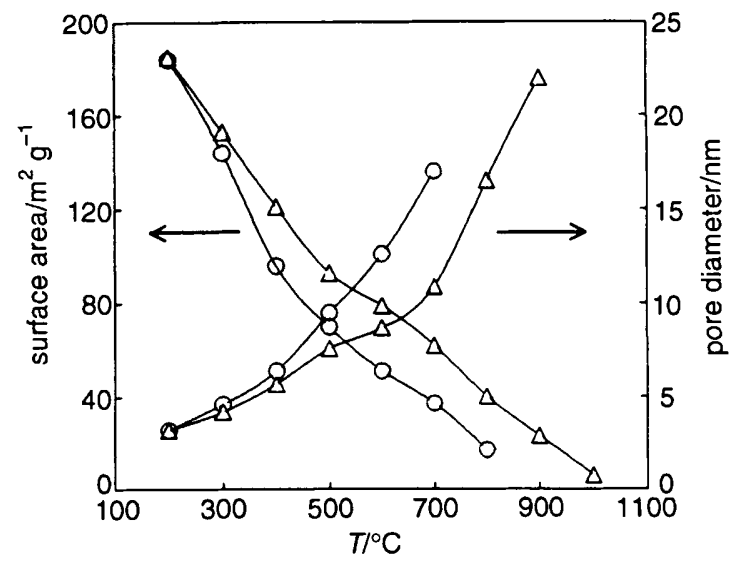

Fig. 8 Surface area and average pore diameter of rutile membranes $\left(18.5 \mathrm{~mol}^{\%} \quad \mathrm{SnO}_{2}\right)$ with $(\triangle)$ and without $(O)$ alumina $(9 \mathrm{wt} . \%$ ) calcined at different temperatures for $8 \mathrm{~h}$

hysteresis, which is a combination of $\mathrm{H} 2$ and $\mathrm{H} 1 .^{28.29} \mathrm{H} 2$ represents a hysteresis with a sloping adsorption branch and a steep desorption branch which is perpendicular to the relative pressure axis. The $\mathrm{H} 2$ type is often associated with a distribution of pore sizes and shapes that are not well defined. Ink-bottle type pores may also give $\mathrm{H} 2$-type hysteresis. In $\mathrm{H} 1$ both the desorption and the adsorption branches are more or less parallel, and parallel to the $y$ axis (amount adsorbed). H1-type hysteresis is often associated with cylindrically shaped pores. Precisely relating the shape of the hysteresis to the pore shape is still a matter of discussion. ${ }^{28}$ It is interesting to note that the isotherm corresponding to the anatase gel gives a typical type I isotherm without any hysteresis loop, ${ }^{7}$ indicating a microporous structure. The most important difference between these two gels is the difference in the size of the primary particles. The anatase membranes contain primary particles of less than $6 \mathrm{~nm}$, where as in the case of rutile membrane the primary particle size is in the range $8-10 \mathrm{~nm}$. The smaller the primary particle the larger the chance to get microporous material. At $300{ }^{\circ} \mathrm{C}$ the shape of the hysteresis has changed to $\mathrm{H} 2$ type and the total volume adsorbed has increased. The increase in the volume adsorbed can be attributed to the increase in the mesoporosity (porosity of $c a$. $40 \%$ at $300{ }^{\circ} \mathrm{C}$ ) by the removal of nitrate and organics. Above $300{ }^{\circ} \mathrm{C}$ the total volume adsorbed decreases with temperature and the hysteresis shifts to the higher $P / P_{\mathrm{o}}$ side, indicating pore growth.

Fig $7(a)$ and $(b)$ represent the porosity and pore size distribution of rutile membranes containing $18.5 \mathrm{~mol}_{\%}$ of $\mathrm{SnO}_{2}$. Calcinations were carried out for either $5 \mathrm{~min}$ or $8 \mathrm{~h}$. Even at $800{ }^{\circ} \mathrm{C}$ the membranes retained a porosity of $c a .40 \%$. The pores have grown from $3.5 \mathrm{~nm}\left(\right.$ at $200{ }^{\circ} \mathrm{C}$ ) to $20 \mathrm{~nm}$ at $700{ }^{\circ} \mathrm{C}$ and the porosity remained constant in the range of $300-800{ }^{\circ} \mathrm{C}$. The initial narrow pore-size distribution becomes broader with increasing temperature [Fig. $7(b)]$.

Fig. 8 represents the pore growth and surface area reduction with temperature of rutile membranes $\left(18.5 \mathrm{~mol} \% \mathrm{SnO}_{2}\right)$ doped with $9 \mathrm{wt} . \%$ alumina. At $200{ }^{\circ} \mathrm{C}$ the surface area of both doped and undoped membranes are more or less the

Table 1 Crystallite size, porosity, pore diameter and geometric (calculated) and measured surface area of rutile membranes $\left(18.5\right.$ mol\% $\mathrm{SnO}_{2}$ ) with and without alumina $(9 \mathrm{wt} . \%)$ at $800^{\circ} \mathrm{C}$ for $8 \mathrm{~h}$

\begin{tabular}{lccc}
\hline \multicolumn{1}{c}{$\begin{array}{c}\text { sample } \\
\text { description }\end{array}$} & $\begin{array}{c}\text { cryst. } \\
\text { diameter } / \mathrm{nm}\end{array}$ & $\begin{array}{c}\text { geometrical } \\
\text { surface area } / \mathrm{m}^{2} \mathrm{~g}^{-1}\end{array}$ & $\begin{array}{c}\% \text { porosity and } \\
(\mathrm{pore} \text { diameter/nm) }\end{array}$ \\
\hline rutile membrane & 71 & 21 & 18 \\
rutile membrane with alumina & 29 & 57 & $40(24)$ \\
\hline
\end{tabular}


same. This indicates that the contribution to the surface area of the sample by the alumina phase can be neglected. With an increase in temperature the difference in surface area between doped and undoped rutile membranes increases and the difference remains constant after $c a .500{ }^{\circ} \mathrm{C}$. It is clear that the alumina doping prevents the grain growth in rutile membranes and can retain a surface area of $c a .20 \mathrm{~m}^{2} \mathrm{~g}^{-1}$, even after heat treatment at $900^{\circ} \mathrm{C}$ for $8 \mathrm{~h}$, with a pore diameter of $c a .23 \mathrm{~nm}$. In Table 1 the crystallite size, porosity, geometrical (calculated) and measured surface area of rutile membranes calcined at $800{ }^{\circ} \mathrm{C}$ with and without alumina is given. The geometrical surface area can be calculated by the equation given below, assuming the crystallites to be spherical:

$$
S_{\mathrm{GEO}}=3 / r d
$$

where $r$ is the radius of the crystallite calculated from XRD line-broadening results. $d\left(=4.7 \mathrm{~g} \mathrm{~cm}^{-3}\right)$ is the skeletal density of the membrane. The crystallite size of the samples containing alumina is $c a$. $50-60 \%$ smaller than that of undoped samples. The alumina addition to the rutile membrane effectively suppresses the grain growth. From Table 1 it can be seen that

(a)

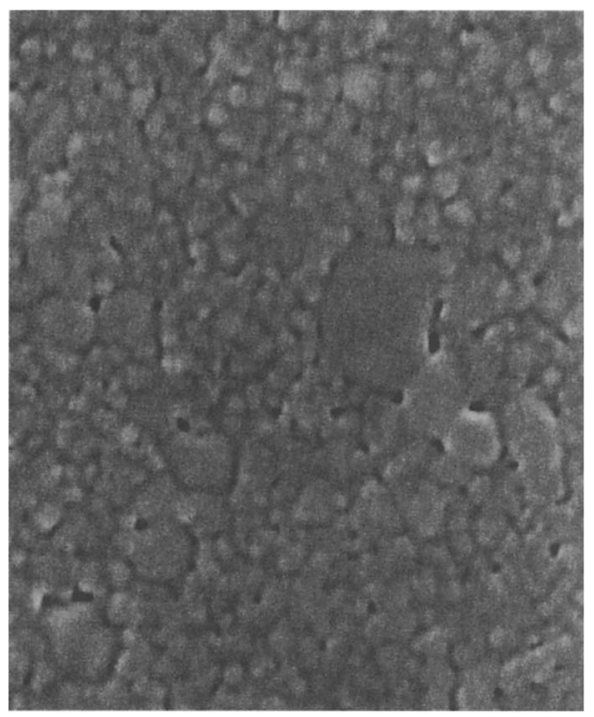

(c)

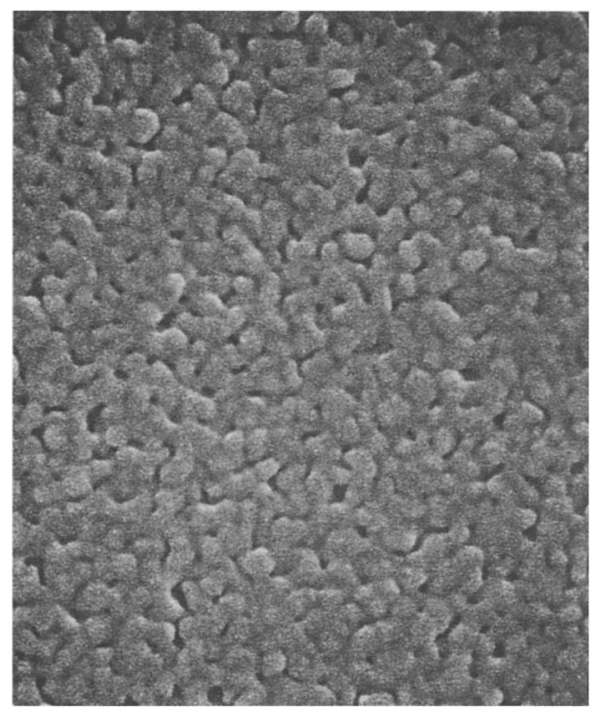

the calculated geometrical surface area is larger than that of the BET surface area. This is a clear indication of particleparticle neck growth.

\section{Comparison of Membranes prepared from Anatase and Rutile Sols}

Fig. $9(a)-(d)$ give the FE-SEM micrographs of unsupported membranes prepared from anatase $[(a)$ and $(b)]$ and rutile $[(c)$ and $(d)]$ sols heated at $450{ }^{\circ} \mathrm{C}[(a)$ and $(c)]$ and $600{ }^{\circ} \mathrm{C}[(b)$ and $(d)]$ for $8 \mathrm{~h}$. At $450^{\circ} \mathrm{C}$ [Fig. $9(a)$ ] the membrane prepared from the anatase sol contains two phases. ${ }^{7}$ The smaller particles represent the anatase phase and the average grain size of the anatase phase is in the same range as that of the average grain size of the rutile membrane given in Fig. $9(\mathrm{c})$. At $450{ }^{\circ} \mathrm{C}$ the rutile membrane has a very uniform singlephase microstructure. At $600{ }^{\circ} \mathrm{C}$ a membrane derived from the anatase sol is completely dense and transformed to rutile, the average grain size is $c a$. $60 \mathrm{~nm}$ [Fig. $9(b)$ ]. The rutile membrane is still porous and has crystallites of $c a .25 \mathrm{~nm}$ in diameter [Fig. $9(d)]$.

(b)

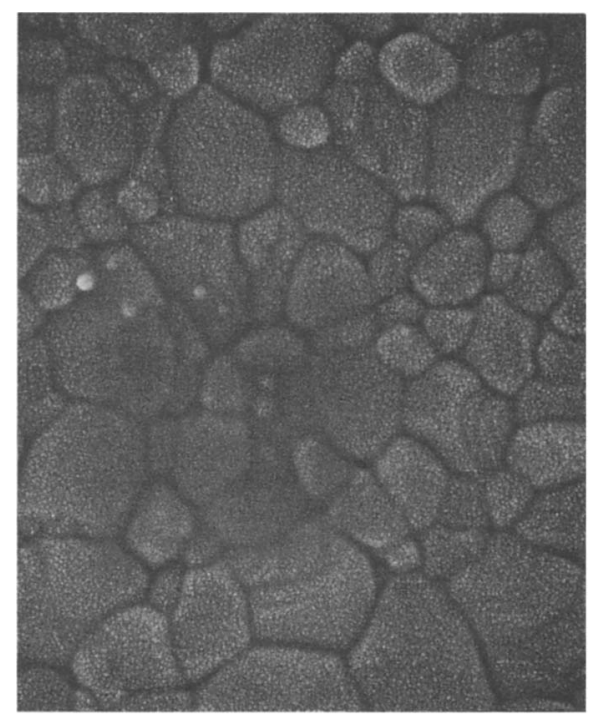

(d)

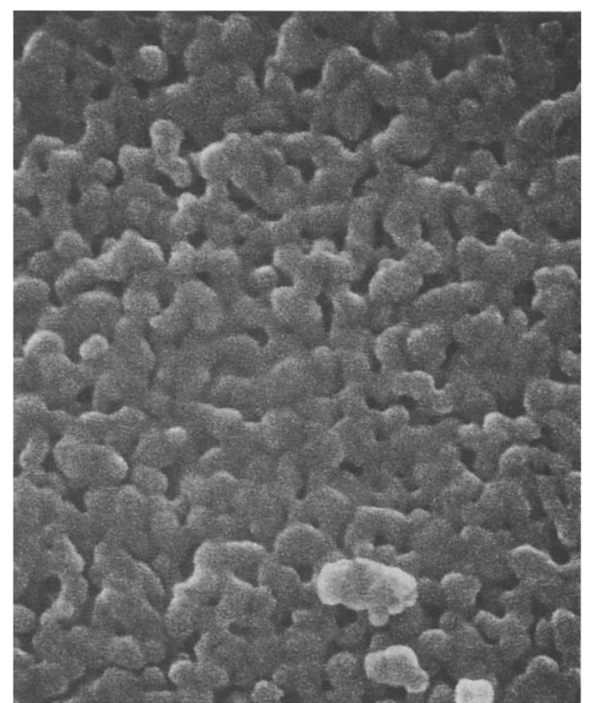

Fig. 9 FE-SEM pictures of unsupported membranes prepared from an anatase sol heated at $(a) 450$ and $(b) 600{ }^{\circ} \mathrm{C}$, and rutile membranes $\left(18.5 \mathrm{~mol}^{\circ} \mathrm{SnO}_{2}\right)$ heated at $(c) 450$ and $(d) 600{ }^{\circ} \mathrm{C}$, for $8 \mathrm{~h}$ 
(a)

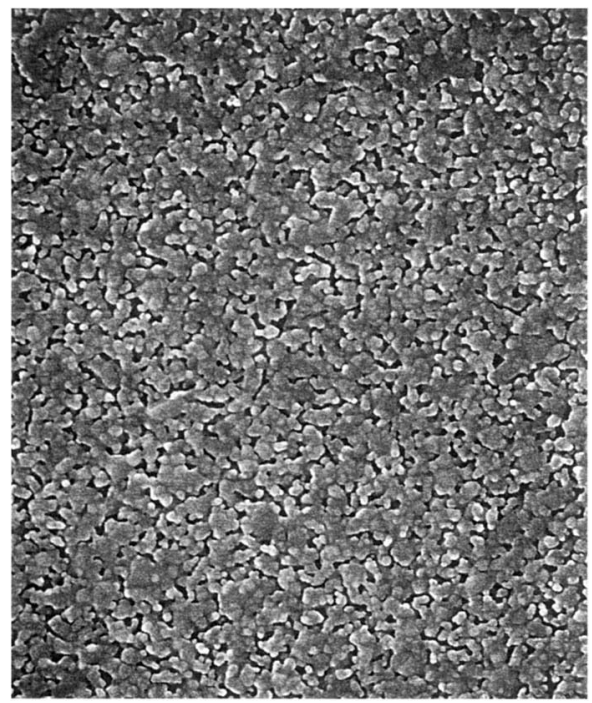

(c)

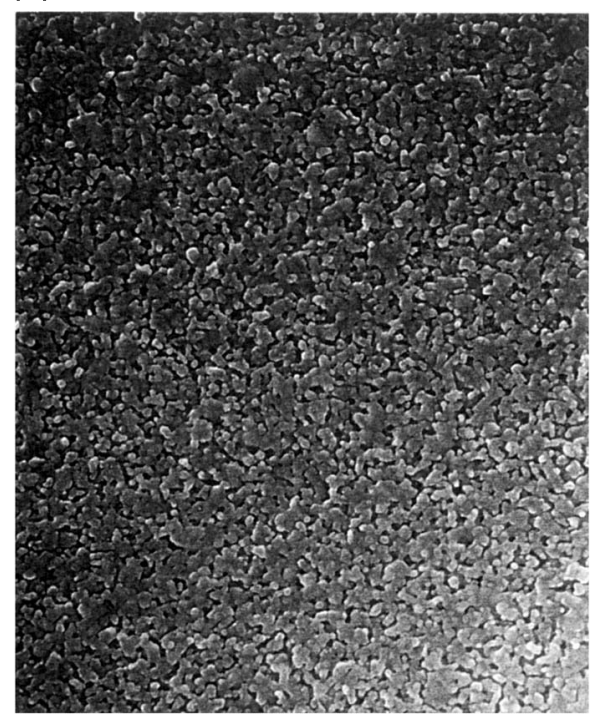

(b)

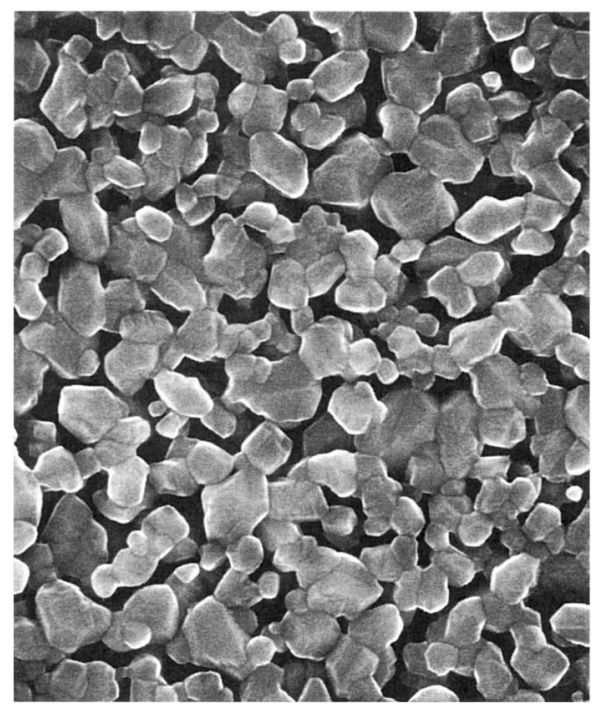

(d)

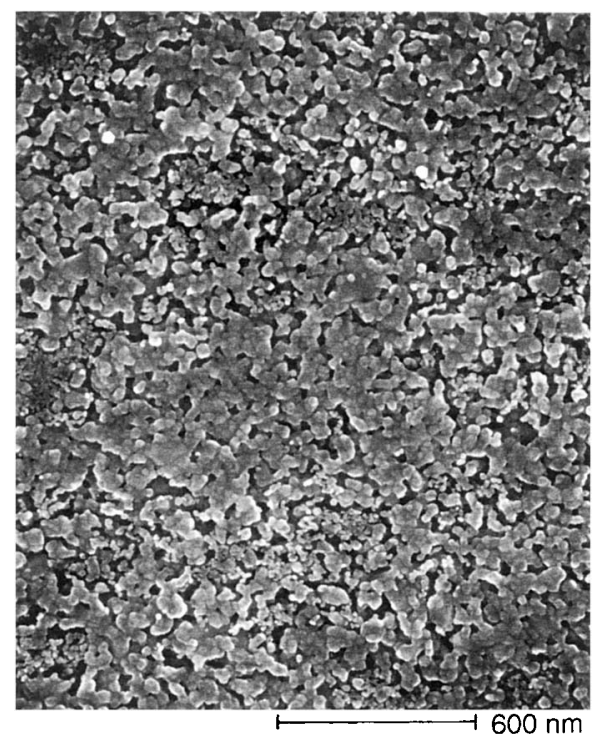

Fig. 10 FE-SEM pictures of $(a, c)$ supported and $(b, d)$ unsupported rutile membranes $\left(18.5 \mathrm{~mol}_{0} \mathrm{SnO}_{2}\right)$ containing $(a, b)$ no alumina and $(c, d)$ 9 wt.\% alumina calcined at $850{ }^{\circ} \mathrm{C}$

\section{Texture of Supported Membranes}

It has been shown ${ }^{8}$ that the supported titania membranes retained a porosity of $c a .25-30 \%$ at $700{ }^{\circ} \mathrm{C}$, whereas the unsupported counterpart retained very little porosity above $500{ }^{\circ} \mathrm{C}$. This positive effect of the support constraint can be seen in supported rutile membranes also. Fig. 10 gave the FESEM micrographs of the rutile membranes with and without alumina $(9 \mathrm{wt} . \%)$ heated at $850^{\circ} \mathrm{C}$ for $8 \mathrm{~h}$. Fig. $10(a)$ and $(c)$ represent the supported rutile membranes without and with $(9$ wt.\%) alumina and Fig. $10(b)$ and $(d)$ represent unsupported membranes without and with alumina, respectively. There is a clear difference in the crystallite and the pore size between supported and unsupported membranes and the difference is more predominant in the composition without alumina. The crystallite sizes of alumina-free rutile membranes are $c a$. 60 and $130 \mathrm{~nm}$ and the average pore sizes are $c a .20$ and $80 \mathrm{~nm}$ for supported and unsupported ones, respectively. In the case of supported membranes the difference between aluminacontaining and alumina-free membranes are not that remarkable [Fig. $9(a)$ and (c), crystallite size ca. $60 \mathrm{~nm}$ in both cases], whereas the difference is quite appreciable in the case of unsupported membranes [Fig. $9(b)$ and $(d)$ ], especially in the crystallite size (130 and $70 \mathrm{~nm})$. This difference may again be due to the support constraint, which retards the pore and crystallite growth.

\section{Conclusions}

Rutile membrane precursor sols have been synthesized by the precipitation of titania on $\mathrm{SnO}_{2}$ nuclei during hydrolysis. The minimum amount of $\mathrm{SnO}_{2}$ necessary to obtain the pure rutile phase was found to be $\mathrm{ca}$. $19 \mathrm{~mol} \%$.

The non-supported, rutile membrane retains a surface area, porosity and pore diameter of $c a .20 \mathrm{~m}^{2} \mathrm{~g}^{-1}, 40 \%$ and $24 \mathrm{~nm}$, respectively, after heat treatment at $800{ }^{\circ} \mathrm{C}$ for $8 \mathrm{~h}$.

Alumina doping prevents the grain growth in rutile membranes and can retain a surface area of $c a .20 \mathrm{~m}^{2} \mathrm{~g}^{-1}$, even after heat treatment at $900{ }^{\circ} \mathrm{C}$ for $8 \mathrm{~h}$, with a pore diameter of $c a .23 \mathrm{~nm}$ and a particle size of $c a .70 \mathrm{~nm}$.

The average pore and crystallite size of supported rutile membranes are $c a .20$ and $60 \mathrm{~nm}$ (from FE-SEM), respectively, and they are smaller than these of their unsupported counter- 
parts. The crystallite size of the unsupported membranes is ca. $130 \mathrm{~nm}$ (from FE-SEM). All the above values are for membranes heated at $850^{\circ} \mathrm{C}$ for $8 \mathrm{~h}$.

\section{References}

1 Encyclopedia of Chemical Technology, ed. R. E. Kirk and D. F. Othmer, Wiley Interscience, New York, 3rd edn., 1980, vol. 12 , p. 952.

2 A. T. Ashcroft, A. K. Cheetham, J. S. Foord, M. L. H. Green, C. P. Grey, A. T. Murrell and P. D. F. Vernon, Nature (London), $1990,344,319$.

3 V. T. Zaspalis, W. van Praag, K. Keizer, J. G. van Ommen, A. J. Burggraaf and J. R. H. Ross, Appl. Catal., 1991, 74, 205.

4 V. T. Zaspalis, W. van Praag, K. Keizer, J. G. van Ommen, A. J. Burggraaf and J. R. H. Ross, Appl. Catal., 1991, 74, 249.

5 V. T. Zaspalis, K. Keizer, J. G. van Ommen, A. J. Burggraaf and J. R. H. Ross, Appl. Catal., 1991, 74, 223.

6 V. T. Zaspalis, K. Keizer, J. G. van Ommen, A. J. Burggraaf and J. R. H. Ross, Appl. Catal., 1991, 74, 235.

7 Krishnankutty-Nair P. Kumar, K. Keizer and A. J. Burggraaf, J. Mater.Chem., submitted.

8 Krishnankutty-Nair P. Kumar, Ph.D. Thesis, University of Twente, 7500 AE Enschede, The Netherlands, 1993.

9 V. T. Zaspalis, Ph.D. Thesis, University of Twente, Enschede, The Netherlands, 1990.

10 A. J. Burggraaf and K. Keizer, in Inorganic Membranes, ed. R. R. Bhave, Van Nostrand Reinhold, New York, 1991, ch. 1.

11 E. F. Heald and C. W. Weiss, Am. Mineral., 1972, 57, 10.
12 F. C. Kracek, U.S. Geol. Surv., 1963, 1144-D, 81.

13 R. D. Shannon and J. A. Pask, J. Am. Ceram. Soc., 1965, 48, 391.

14 A. I. Sheinkman, V. A. Tyumentsev and A. A. Fotiev, Izv. Akad. Nauk SSSR, Neorg. Mater., 1984, 20, 1692.

15 U. Balachandran and N. G. Eror, J. Solid State Chem., 1982, 42, 276.

16 Y. Iida and S. Ozaki, J. Am. Ceram. Soc., 1961, 44, 120.

17 H. Knoll and U. Kühnhold, Naturwissenschaften., 1957, 44, 394.

18 A. W. Czanderna, C. N. R. Rao and J. M. Honing, Trans. Faraday Soc., 1958, 54, 1069.

19 C. N. R. Rao, Can. J. Chem., 1961, 39, 498

20 F. Dachille, P. Y. Simens and R. Roy, Am. Mineral., 1968, 53, 1929.

21 A. Matthews, Am. Mineral., 1976, 61, 419.

22 R. D. Shannon, J. Appl. Phys., 1964, 35, 3414.

23 K. P. Kumar, K. Keizer, A. J. Burggraaf, T. Okubo, H. Nagamoto and S. Morooka, Nature (London), 1992, 358, 48.

24 S. Komerneni, E. Breval and R. Roy, J. Non-Cryst. Solids, 1986, 79, 195.

25 W. N. Schreiner and R. Jenkins, Adv. X-ray Anal., 1983, 26, 123.

26 D. W. Marquardt, J. Soc. Ind. Appl. Maths., 1963, 11, 431.

27 H. P. Klug and L. E. Alexander, X-ray Diffraction Procedures, Wiley, New York, 1974, p. 635.

28 K. S. W. Sing, D. H. Everett, R. A. W. Haul, L. Moscou, R. A. Pierotti, J. Rouquerol and T. Siemieniewska, Pure Appl. Chem., 1985, 57, 603.

29 J. H. de Boer, in The Structure and Properties of Porous Materials, ed. D. H. Everett and F. S. Stone, Butterworth, London, 1958, p. 68.

Paper 3/02256K; Received 20th April, 1993 